\title{
Comparative corrosion protection studies of electroactive/non-electroactive epoxy thermoset composites containing conductive rGO/non-conductive GO platelets
}

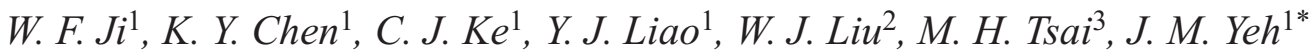 \\ ${ }^{1}$ Department of Chemistry and R\&D Center for Membrane Technology, Chung-Yuan Christian University (CYCU), \\ 32023 Chung Li, Taiwan, R.O.C. \\ ${ }^{2}$ Department of Chemical Engineering, CYCU, 32023 Chung Li, Taiwan, R.O.C. \\ ${ }^{3} \mathrm{PhD}$ Program, Graduate Institute of Precision Manufacturing, National Chin-Yi University of Technology, \\ 41170 Taichung, Taiwan, R.O.C.
}

Received 17 October 2018; accepted in revised form 11 February 2019

\begin{abstract}
In this study, comparative corrosion protection studies of cold-rolled steel (CRS) electrodes coated with electroactive/non-electroactive epoxy thermoset (denoted as EET/NEET) composites containing dispersed reduced graphene oxide ( $\mathrm{rGO}$ ) and graphene oxide (GO) platelets are presented. All composites were obtained through the thermal ring-opening reaction of bisphenol A diglycidyl ether (DGEBA) with amino-capped aniline trimer (ACAT) or trimethylolpropane tris[poly(propylene glycol), amine terminated] ether (T-403) at a specific mixing ratio in the presence of dispersed $\mathrm{rGO} / \mathrm{GO}$ were characterized Fourier Transform Infrared (FTIR) spectroscopy and Transmission Electron Microscopy (TEM). In gas permeability measurements, the GO was found to display a slightly better dispersion capability in both EET and NEET membrane than in rGO. Conductive rGO platelets were found to promote the redox behavior of EET and non-conductive GO platelets was found to depress the redox behavior of EET, as measured by electrochemical cyclic voltammetry (CV) studies. Corrosion protection of composite coatings was investigated by electrochemical corrosion measurements in saline solution. It should be noted, in the EET system, that rGO was found to exhibit better anticorrosion performance as compared to that of GO. However, in NEET system, GO was found to have better anticorrosion performance than rGO. Better anticorrosion of $\mathrm{rGO}$ in EET may be attributed to better synergistic effect of electro-catalytic and the oxygen barrier properties of rGO in EET. On the contrary, better anticorrosion of GO in NEET may be associated with better oxygen barrier property of GO alone in NEET than that of rGO. The passive metal oxide layer formed on the cold rolled steel (CRS) electrode induced by EET was further confirmed by Raman and Electron Spectroscopy for Chemical Analysis (ESCA).
\end{abstract}

Keywords: polymer composites, corrosion, epoxy, electroactive, graphene oxide

\section{Introduction}

Corrosion control is a significant topic that attracts interest from the current metallic finishing industry. Many coating materials designed for corrosion protection of metal surfaces have been explored [1-3]. Nowadays, one of the standard industrial practices is to treat the metal surfaces with compounds containing chromium. However, there is much concern about adverse environmental and health effects of chromium compounds $[4,5]$. For this reason, there has been a growing interest in developing coatings using safer polymeric materials that can be classified into two main groups: electroactive polymers and polymer composites. Anticorrosion coatings resulting from electroactive polymers such as polyaniline [6-8], polythiophene [9-11] and polypyrrole $[12,13]$ have 
evoked great research interest in the past decades due to their reversibly electro-catalytic (i.e., redox) capability leading to the formation of a densely passive metal oxide layer to protect the underlying metallic substrate, as revealed by Wessling [14]. Anticorrosion coatings prepared from electroactive oligomerbased polymers also evoked intensive and extensive research activities [15-18]. For example, anticorrosive coatings prepared from aniline-oligomer based electroactive polyimide [15], electroactive polyamide [16], electroactive polyurethane [17] and electroactive epoxy resin [18] have been reported to exhibit better corrosion protection compared to corresponding non-electroactive polymer coatings.

On the other hand, anticorrosion coatings originating from polymer composites have also attracted great research interests. The primary effect of a polymer coating is to function as a physical barrier against aggressive species such as $\mathrm{O}_{2}$ and $\mathrm{H}^{+}$. However, all polymeric coatings are not permanently impenetrable, and once defects appear in the coatings, pathways will be generated for the corrosive species to attack the metallic substrate, and localized corrosion will appear. Therefore, as a second layer of protection for corrosion, various inorganic fillers with spherical shape (e.g., silica [19], titania [20]) or plate-like (e.g., clay [21]) fillers have been incorporated into various polymeric coatings to effectively increase the length of diffusion pathways of oxygen and water. For example, montmorillonite (MMT), the most commonly used layered material in polymer-based composites, can be delaminated into $1 \mathrm{~nm}$ thick, two-dimensional nanosheets that are $\sim 200 \mathrm{~nm}$ in length in versatile polymers for anticorrosion coating application [22].

Recently, research works associated with graphene oxide-based polymer composites have also evoked much interest due to many unique mechanical [23], thermal [24], electrical [25] and gas barrier [26] properties of dispersed graphene/graphene oxide platelets embedded into polymers. Compared to clay platelets with aspect ratios of $\sim 200$, the graphene platelets with higher aspect ratios of $\sim 500$ dispersed in polystyrene were found to exhibit better barrier properties for oxygen gas [27]. It implies that the graphene-based polymeric composite coatings may reveal better corrosion protection on metallic substrates compared to clay-based polymeric composite coatings, which may be attributed to the well-dispersion of the high aspect ratio of graphene platelets, leading to the formation of graphene-based polymer composite coatings with better oxygen gas barrier property. For example, Chang et al. [28] reported that the GO-based polyaniline (PANI) coating displayed better anticorrosion performance compared to clay-based PANI coatings. Moreover, Yu et al. [29] explored that the PS-GO composite coatings were found to exhibit better anticorrosion performance than neat PS base on a series of electrochemical corrosion measurements.

Based on literature review, anticorrosion coatings in terms of GO-based epoxy composites were found to attract extensive academic and industrial research interests than other GO-based polymer composites in the past decades. For example, He et al. [30] presents that incorporation of GO into epoxy resin significantly enhanced anticorrosion performance on the metallic substrate due to the improved corrosion factor in electrolyte barrier properties derived from highly aspect and dispersed graphene platelets in epoxy coating [31]. Thus, epoxy/graphene composite coatings can be considered as promising candidates for protective coatings in the nuclear industry. However, the comparative anticorrosion studies of electroactive epoxy thermoset (EET) composites containing dispersed conductive rGO and non-conductive GO platelets on metallic substrates have never been mentioned.

Therefore, in this study, we attempt to present the first comparative anticorrosion studies for EET composites containing conductive $\mathrm{rGO}$ and non-conductive GO platelets. As a control experiment, the NEET composites were also prepared for comparison. First, rGO is synthesized by the modified Hummers' method and thermal-reduced process, followed by characterization through FTIR, ESCA and Raman spectroscopy. On the other hand, ACAT was synthesized by oxidative coupling. Subsequently, as-prepared ACAT or T-403 was further reacting with DGEBA in a dimethylacetamide (DMAc) solution in the presence of $1 \mathrm{wt} \%$ of rGO and GO platelets, followed by programmed heating to give rGOEET/GOEET. The asprepared EET/NEET composites were characterized by FTIR spectroscopy. The dispersion capability of rGO and GO in both EET and NEET composites was further observed using TEM. The oxygen barrier property of EET and NEET composite membranes was determined using a gas permeability analyzer (GPA). Redox behavior of EET composite coatings was investigated by electrochemical cyclic voltammetry (CV) studies. Finally, comparative anticorrosion studies of CRS electrode coated with EET/NEET 
composites containing dispersed $1 \mathrm{wt} \%$ of conductive $\mathrm{rGO}$ and non-conductive GO platelets was presented by performing a series of electrochemical corrosion measurements (such as Tafel, Nyquist and Bode plots) in saline condition. Eventually, the formation of a densely passive metal oxide layer upon on the CRS electrode was identified by Raman and ESCA spectroscopy.

\section{Experimental section}

\subsection{Materials and instrumentations}

In this study, the bisphenol A diglycidyl ether (DGEBA; Aldrich, 95.0\%; USA) and trimethylolpropanetris[poly(propylene glycol), Trimethylolpropane tris[poly(propylene glycol), amine terminated] ether (T-403; Aldrich, 97.0\%; USA) were used as received without further treatment. Aniline (Aldrich, 97.0\%; USA) was distilled prior to use. 4,4-diaminodiphenylamine sulfate (TCI, 97.0\%; Japan), $N, N^{\prime}$ dimethylacetamide (DMAc; Mallinckrodt/Baker, 99.9\%; USA), sodium chloride ( $\mathrm{NaCl}$; Aldrich, $99.0 \%$; USA), hydrochloric acid ( $\mathrm{HCl}$; Aldrich, 37.0\%; USA) and ammonium hydroxide solution $\left(\mathrm{NH}_{4} \mathrm{OH}\right.$; Aldrich, 28.0-30.0\%; USA) and ammonium persulfate crystals (APS; J. T. Baker, 97.0; USA). All of the chemicals were of reagent grade unless otherwise stated.

The attenuated total reflectance FTIR spectra was obtained at a resolution of $4.0 \mathrm{~cm}^{-1}$ with an FTIR spectrometer (FT/IR-4200) at room temperature ranged from 4000 to $650 \mathrm{~cm}^{-1}$. Mass spectra were run on a Bruker Daltonics IT mass spectrometer model Esquire 2000 (Leipzig, German) with an Agilent ESI source (model G1607-6001). TEM images of nanostructure composite materials were obtained with a JEOL-200FX instrument operated at an accelerating voltage of $120 \mathrm{kV}$. Samples for TEM study were cut into 60-90 nm thick sections with a diamond knife. The sample for cyclic voltammetry was coated on ITO glass and measured by a VoltaLab 50 (PST050) potentiostat/galvanostat with scan rate $50 \mathrm{mV} / \mathrm{s}$ in the $1.0 \mathrm{M} \mathrm{H}_{2} \mathrm{SO}_{4}$. A Yanagimoto Co. Ltd. Gas permeability analyzer (model GTR10) was employed to perform the permeation experiment of oxygen gas, the pressure of measured data was maintained at $392 \mathrm{kPa}$. Differential scanning calorimetry (DSC) was performed on a DuPont TA Q10 differential scanning calorimeter at a heating or cooling rate of $5^{\circ} \mathrm{C} / \mathrm{min}$ in air atmosphere.
Electrochemical measurements of corrosion potential and corrosion current of sample-coated coldrolled steel (CRS) electrodes were obtained using VoltaLab 50 (PST050) potentiostat/galvanostat. An electrochemical impedance spectroscopy (EIS) study was done on an AutoLab (PGSTAT302N) potentiostat/galvanostat electrochemical analyzer, all the measured data were obtained in $25 \pm 1{ }^{\circ} \mathrm{C}$. Raman spectra were used to characterize the passive layer and this was carried out by a micro Raman spectroscopy system with laser wavelength of $532 \mathrm{~nm}$ as excitation source and from an argon ion laser at $20 \mathrm{~mW}$. Electron spectroscopy was measured using chemical analysis (ESCA), (VG Scientific ESCALAB 250).

\subsection{Synthesis of graphene oxide (GO) and reduce graphene oxides (rGO)}

A representative procedure to prepare the $\mathrm{GO}$ and rGO is given as follows: (GO derived from SFG44 synthetic graphite powder $\left(\mathrm{TIMCAL}^{\circledR}\right)$ was prepared by Hummers' method) $4.0 \mathrm{~g}$ of synthetic graphite powder and $2.0 \mathrm{~g}$ of $\mathrm{NaNO}_{3}$ were deposited into $280 \mathrm{ml}$ of concentrated $\mathrm{H}_{2} \mathrm{SO}_{4}$ solution while stirring for 2 hours. Then, $16 \mathrm{~g}$ of $\mathrm{KMnO}_{4}$ was added gently into the flask with an ice/water bath for 2 hours. The mixture was further diluted by $400 \mathrm{ml}$ of de-ionized water. After that, $5 \mathrm{wt} \%$ of $\mathrm{H}_{2} \mathrm{O}_{2}$ was introduced into solution until color of mixture changed to brown, indicating that $\mathrm{KMnO}_{4}$ was fully reduced. The as-prepared GO slurry was redispersed in a suitable amount of de-ionized water. Subsequently, the GO solution was washed with excess amount of distilled water to remove residual acid until $\mathrm{pH}$ of solution reached $\sim 5$. The final product of GO powder was dried at $50^{\circ} \mathrm{C}$ in a vacuum oven. Subsequently, the $\mathrm{GO}$ powder was maintained in a furnace at $1000^{\circ} \mathrm{C}$ in argon for about 30 seconds for reduction. Finally, the rGO was obtained as powder [32].

\subsection{Preparation of amino-capper aniline trimer (ACAT)}

The compounds 4, 4'-diaminodiphenylamine sulfate (4.73 g, 0.016 mole) and aniline (1.48 g, 0.016 mole) were dissolved in an aqueous $\mathrm{HCl}$ solution $(1.0 \mathrm{~N}$, $150 \mathrm{ml}$ ) containing $15 \mathrm{~g}$ of $\mathrm{NaCl}$. A solution of ammonium persulfate $(3.6 \mathrm{~g}, 0.016 \mathrm{~mole})$ in aqueous $\mathrm{HCl}(1.0 \mathrm{~N}, 25 \mathrm{ml})$ was added via a dropping funnel into the above solution at $5{ }^{\circ} \mathrm{C}$ at a rate of approximately $60 \mathrm{drops} / \mathrm{min}$. The reaction mixture was stirred 
for 1 hour at an operational temperature of $5^{\circ} \mathrm{C}$. The resulting precipitate was collected by filtration, followed by washing with large amount of aqueous $\mathrm{HCl}$ solution $(1.0 \mathrm{~N}, 400 \mathrm{ml})$. The solid as-obtained product was washed with $\mathrm{NH}_{4} \mathrm{OH}$ solution $(1.0 \mathrm{~N}, 100 \mathrm{ml})$ and followed by an excess amount of distilled water. Subsequently, the obtained blue powder was further dried in a vacuum oven at an operational temperature of $50^{\circ} \mathrm{C}$ for 24 hours. The as-obtained ACAT was obtained as a blue solid with the yield of $\sim c a .40 \%$ [33].

\subsection{Preparation of electroactive epoxy thermoset (EET) composite coating/membrane}

To prepare the EET coating/membrane, a representative procedure was given as follows: First, $0.945 \mathrm{~g}$ of DGEBA was dissolved in $15.0 \mathrm{~g}$ of DMAc through stirring (denoted as beaker A). Subsequently, $0.0845 \mathrm{~g}$ of aniline trimer was introduced to beaker $A$ under magnetic stirring for 3 hours (denoted as beaker $\mathrm{A}^{\prime}$ ). Next, $0.34 \mathrm{~g}$ of T-403 was poured into beaker $\mathrm{A}^{\prime}$ under magnetic stirring for an additional 12 hours. Finally, the solution of beaker $\mathrm{A}^{\prime}$ was cast onto the surface of CRS electrode $\left(1 \times 1 \mathrm{~cm}^{2}\right)$ and the surface of PTFE template $\left(6 \times 6 \mathrm{~cm}^{2}\right)$, and then treated with programmed heating at $50^{\circ} \mathrm{C}$ for 1 hour, $120^{\circ} \mathrm{C}$ for 2 hours and $140^{\circ} \mathrm{C}$ for 30 minutes. Eventually, the CRS electrode coated with EET ( $\sim 20 \mu \mathrm{m}$ in coating thickness) and the EET free-standing membrane ( $~ 80 \mu \mathrm{m}$ in membrane thickness) were obtained.

To prepare the EET composite coatings/membranes, the representative procedure is as follows: First, $0.945 \mathrm{~g}$ of DGEBA was dissolved in $15.0 \mathrm{~g}$ of DMAc under magnetic stirring, denoted as beaker A. Next, $0.0845 \mathrm{~g}$ of aniline trimer was introduced into beaker A under magnetic stirring for 3 hours, denoted as beaker $\mathrm{A}^{\prime}$. After this, $0.34 \mathrm{~g}$ of T-403 was poured into beaker $\mathrm{A}^{\prime}$ under magnetic stirring for $\sim 1$ minute, denoted as beaker $\mathrm{A}^{\prime}$. Finally, $0.0138 \mathrm{~g}$ of $\mathrm{GO} / \mathrm{rGO}$ fine powder was incorporated into beaker $\mathrm{A}^{\prime}$ under magnetic stirring for an additional 12 hours. The asprepared mixing solution in beaker $\mathrm{A}^{\prime}$ was then cast onto the surface of CRS electrode $\left(1 \times 1 \mathrm{~cm}^{2}\right)$ and the surface of the PTFE template $\left(6 \times 6 \mathrm{~cm}^{2}\right)$, and then treated with programmed heating at $50^{\circ} \mathrm{C}$ for 1 hour, $120^{\circ} \mathrm{C}$ for 2 hours and $140^{\circ} \mathrm{C}$ for 30 minutes. Eventually, the CRS electrode coated with EET composite coating ( $20 \mu \mathrm{m}$ in coating thickness) and the EET composite free-standing membrane $(\sim 80 \mu \mathrm{m}$ in membrane thickness) were obtained.

\subsection{Preparation of NEET composite coating/membrane}

To prepare the NEET coating/membrane, the representative procedure used is as follows: First, $0.945 \mathrm{~g}$ of DGEBA was dissolved in $15.0 \mathrm{~g}$ of DMAc under magnetic stirring for 30 minutes, denoted as beaker A. Secondly, $0.44 \mathrm{~g}$ of T-403, which functioned as a hardener, was introduced into beaker A under magnetic stirring for an additional 12 hours, denoted as beaker $\mathrm{A}^{\prime}$. Then, the solution was cast onto the surface of the CRS electrode $\left(1 \times 1 \mathrm{~cm}^{2}\right)$ and the surface of the PTFE template $\left(6 \times 6 \mathrm{~cm}^{2}\right)$, and then treated with programmed heating at $50^{\circ} \mathrm{C}$ for 1 hour, $120^{\circ} \mathrm{C}$ for 2 hours and $140^{\circ} \mathrm{C}$ for 30 minutes. Eventually, the CRS electrode coated with NEET ( $\sim 20 \mu \mathrm{m}$ in coating thickness) and the NEET free-standing membrane $(\sim 80 \mu \mathrm{m}$ in membrane thickness) were obtained.

To prepare the NEET composite coating/membrane, the representative procedure used is as follows: First, $0.945 \mathrm{~g}$ of DGEBA was dissolved in $15.0 \mathrm{~g}$ of DMAc under magnetic stirring for 30 minutes, denoted as beaker A. Second, $0.44 \mathrm{~g}$ of T-403, which functioned as a hardener, was blended into beaker A using magnetic stirring for $\sim 1$ minute, denoted as beaker $\mathrm{A}^{\prime}$. Finally, $0.0138 \mathrm{~g}$ of $\mathrm{GO} / \mathrm{rGO}$ fine powder was incorporated into beaker $\mathrm{A}^{\prime}$ under magnetic stirring for an additional 12 hours. The as-prepared mixing solution was then cast onto the surface of the CRS electrode $\left(1 \times 1 \mathrm{~cm}^{2}\right)$ and the surface of the PTFE template $\left(6 \times 6 \mathrm{~cm}^{2}\right)$, and then treated with programmed heating at $50^{\circ} \mathrm{C}$ for 1 hour, $120^{\circ} \mathrm{C}$ for 2 hours and $140^{\circ} \mathrm{C}$ for 30 minutes. Eventually, the CRS electrode coated with the NEET composite coating $(\sim 20 \mu \mathrm{m}$ in coating thickness) and the NEET composite free-standing membrane ( $\sim 80 \mu \mathrm{m}$ in membrane thickness) were obtained. The flowchart to prepare the EET/NEET composites is given in Figure 1.

\subsection{Redox property of materials confirmed by electrochemical CV studies}

In this study, the electroactive (redox) property of as-prepared EET/NEET and their corresponding composite materials (e.g., EET, rGOEET and GOEET//NEET, rGONEET and GONEET) upon indium tin oxide (ITO) electrode was determined using electrochemical cyclic voltammetry (CV) studies. First, the ITO electrode $\left(4 \times 5 \mathrm{~cm}^{2}\right)$ coated with all spin-coated testing materials was obtained from the as-prepared DMAc solution containing EET/NEET 


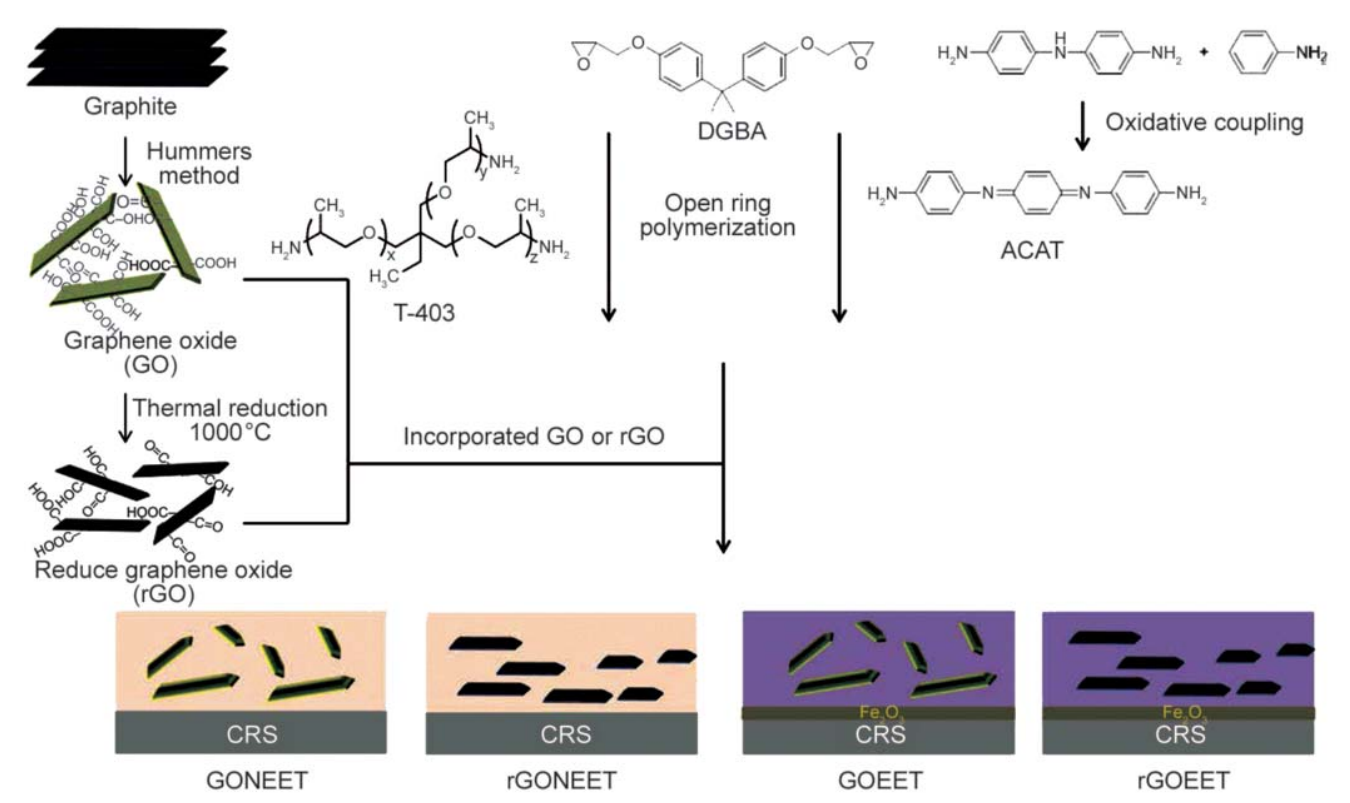

Figure 1. Flowchart for the preparation of EET and NEET composites.

and corresponding composite materials, followed by a programmed heating treatment of $120^{\circ} \mathrm{C}$ for 1 hour. The as-prepared ITO electrode coated with all spincoated materials functioned as a working electrode. A platinum foil served as auxiliary electrode while an $\mathrm{Hg} / \mathrm{HgCl}$ (3.0 M KCl solution) electrode was used as reference electrode, respectively. Cyclic voltammetry (CV) was conducted using a VoltaLab 50 (potentiostat/galvanostat) electrochemical workstation with a scan rate of $50 \mathrm{mV} / \mathrm{s}$ measured in $150 \mathrm{ml}$ of $1.0 \mathrm{~N} \mathrm{H}_{2} \mathrm{SO}_{4}$ aqueous solution. All electrochemical $\mathrm{CV}$ measurements were performed in a double-wall jacketed cell at a constant operational temperature of $25^{\circ} \mathrm{C}$.

\subsection{Electrochemical corrosion studies of CRS coated with all prepared materials}

In this study, CRS electrode coated with all epoxy coatings of $\sim 20 \mu \mathrm{m}$ in thickness were obtained. Edges of the CRS electrode were sealed with super-fast epoxy cement $\left(\operatorname{SPAR}^{\circledR}\right)$. The coated and uncoated CRS electrodes were connected to the working electrode of an electrochemical cell. For the anticorrosion measurement aspect, polarization curves were obtained using cyclic voltammetry (VoltaLab 50 potentiostat/galvanostat) at an operational temperature of $25^{\circ} \mathrm{C}$. The three-electrode configuration was employed in the circuit, with the sample as the working electrode, the graphite rod as the counter electrode, and the saturated calomel electrode (SCE) as the reference electrode. $3.5 \mathrm{wt} \%$ of saline solution was utilized as electrolyte. Open circuit potential (OCP) at equilibrium state of system was used as corrosion potential $\left(E_{\text {corr }}[\mathrm{mV}] v s\right.$. SCE). For potentiodynamic polarization experiments, the potential was scanned from -500 to $500 \mathrm{mV}$ at a scanning rate of $50 \mathrm{mV} \cdot \mathrm{s}^{-1}$. Corrosion current $\left(I_{\text {corr }}\left[\mu \mathrm{A} / \mathrm{cm}^{2}\right]\right)$ was determined by superimposing a straight line along linear portion of cathodic or anodic curve and extrapolating it through $E_{\text {corr }}[\mathrm{mV}]$.

Electrochemical impedance spectroscopy (EIS) measurements under $3.5 \mathrm{wt} \%$ of saline aqueous solution were obtained using AutoLab (PGSTAT302N) potentiostat/galvanostat electrochemical analyzer at room temperature. Impedance measurements of asprepared CRS electrode coated with all testing materials as working electrode were carried out in the frequency range of $10 \mathrm{~Hz}$ to $100 \mathrm{mHz}$. Graphite rod

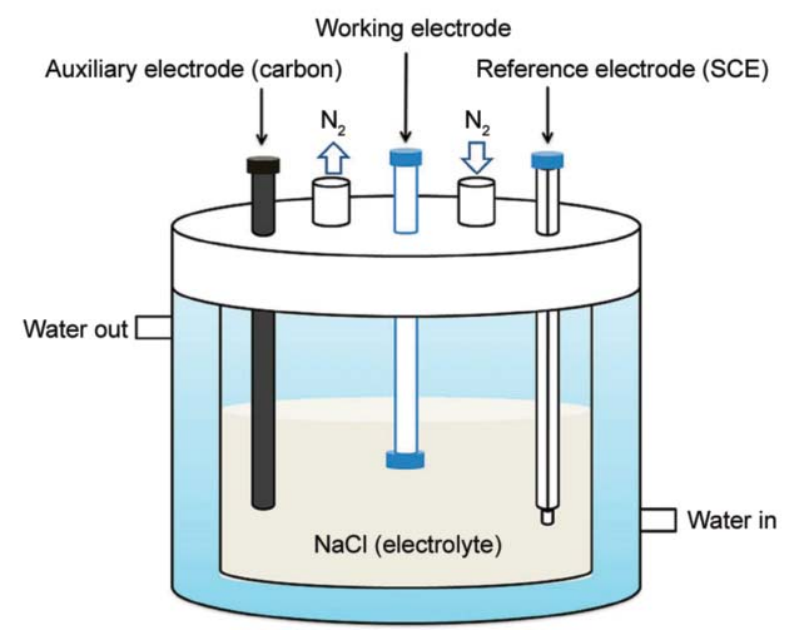

Figure 2. A typical setup of electrochemical corrosion test cell. 
and saturated calomel electrode (SCE) were used as counter electrode and reference electrode, respectively. A typical setup of electrochemical corrosion test cell for CRS electrode coated with all samples is shown in Figure 2. Working electrode was maintained in test environment for 40 minutes before the performance of impedance measurements. All raw data were repeated at least three times to confirm the data reproducibility and statistical significance.

\section{Results and discussion}

In this study, Hummers' method was used to prepare the non-conductive graphene oxide (GO). Subsequently, conductive reduced graphene oxide (rGO) was prepared by thermally reduced process of nonconductive GO. The characterization of as-prepared GO and rGO is shown in Figure 3, as discussed in the following section.

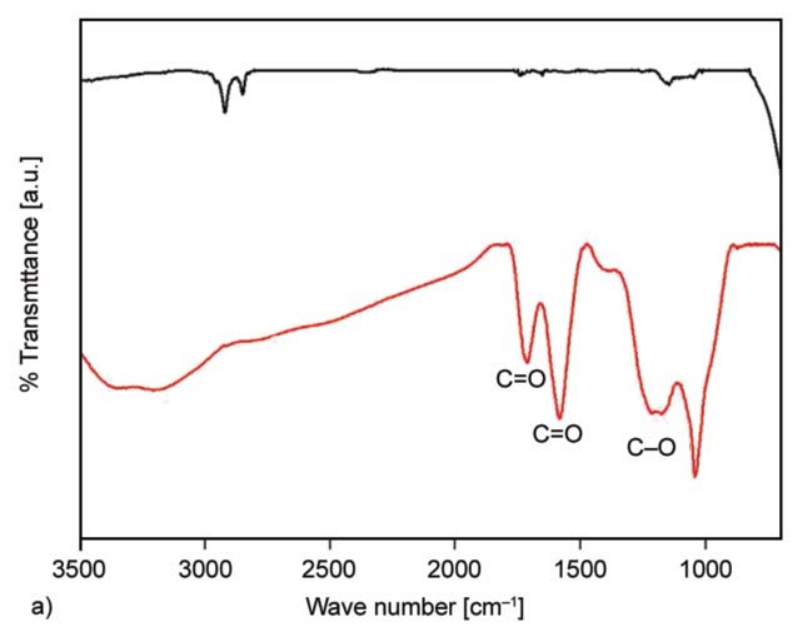

\subsection{Characterization of graphene oxides (GO) and thermally reduced graphene oxides (rGO)}

In this study, the characterization of GO and rGO was identified by FTIR, ESCA and Raman spectroscopy, as shown in Figure 3. Absorption bands of FTIR found at positions of 1717 and $1589 \mathrm{~cm}^{-1}$, which corresponds to stretching of $\mathrm{C}=\mathrm{O}$ from carboxyl and lactone, and in-plane vibration of $\mathrm{sp}^{2}$-hybrid $\mathrm{C}=\mathrm{C}$ of as-prepared GO, are shown in Figure 3a [34]. Overlapped bands that appeared at wavenumber of 1100 $1280 \mathrm{~cm}^{-1}$ was attributed to carbonyl groups (i.e. peroxide, lactol, ether, anhydride, and epoxide groups). Furthermore, strong absorption peak located at the position of $1045 \mathrm{~cm}^{-1}$ was related to the stretching of $\mathrm{C}-\mathrm{OH}$, and possible stretching of $\mathrm{C}-\mathrm{O}$ in ether. As GO was reduced by a thermal process, the FTIR of GO was found to show a dramatic reduction in

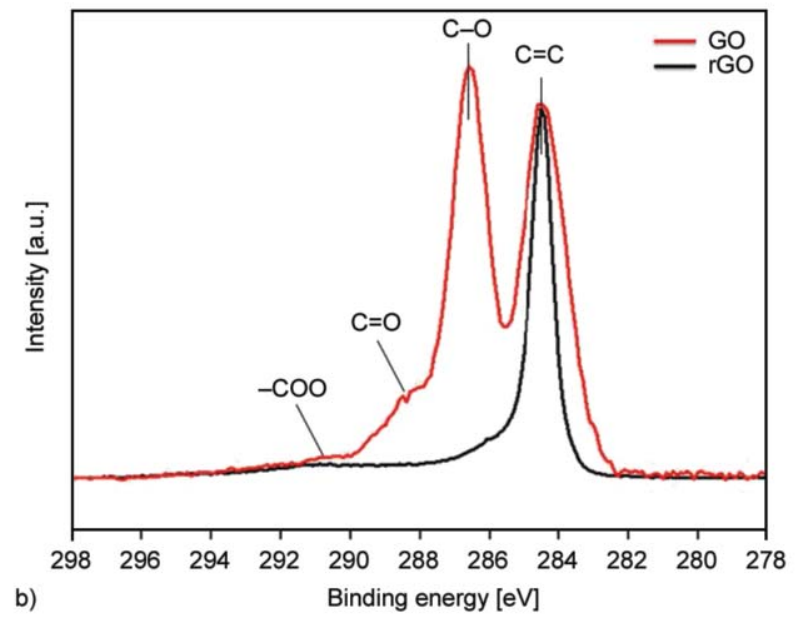

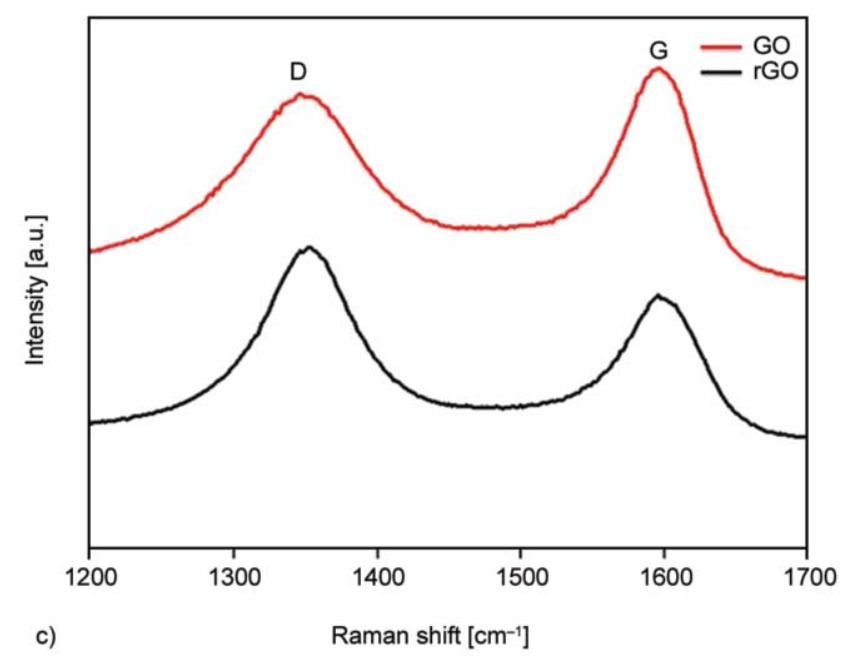

Figure 3. (a) FTIR spectra of rGO and GO, (b) ESCA C1s spectra of rGO and GO, and (c) Raman spectra of rGO and GO. 
intensity of absorption bands at positions of 3000 3500,1717 , and $1045 \mathrm{~cm}^{-1}$, indicating the loss of $\mathrm{C}-\mathrm{OH}, \mathrm{COOH}$ and $\mathrm{H}_{2} \mathrm{O}$, as shown in Figure $3 \mathrm{a}$.

Secondly, the ESCA spectra of C 1s and O 1s of GO and $\mathrm{rGO}$ were shown in Figure $3 \mathrm{~b}$. The $\mathrm{C} 1 \mathrm{~s}$ spectra were normalized by the $\mathrm{C}=\mathrm{C}$ characteristic peak with binding energy of $284.5 \mathrm{eV}$. The $\mathrm{C} 1 \mathrm{~s}$ spectrum of GO showed three peaks assigned to carbonyl groups (i.e. $\mathrm{C}-\mathrm{O}, \mathrm{C}=\mathrm{O}$ and $-\mathrm{COO}$ ), including $\mathrm{C}-\mathrm{O}$ signals from phenol and ether at the position of $286.1 \mathrm{eV}$, $\mathrm{C}=\mathrm{O}$ from carbonyl and quinone at the position of $287.5 \mathrm{eV}$, and $-\mathrm{COO}$ from carboxyl and ester at the position of $288.7 \mathrm{eV}$ [35]. The relative intensity of the $\mathrm{C}-\mathrm{O}$ peak was found to be much larger than those of $\mathrm{C}=\mathrm{O}$ and $-\mathrm{COOH}$. It should also be noted that the reduction/conversion of $\mathrm{GO}$ to $\mathrm{rGO}$ by a thermal process corresponded to the depression in intensity of characteristic absorption peaks of GO. The rGO showed a dramatic reduction in absorption bands at the position of $\mathrm{C}-\mathrm{O}, \mathrm{C}=\mathrm{O}$ and $-\mathrm{COOH}$ peaks, indicating the loss of $\mathrm{C}-\mathrm{OH}, \mathrm{COOH}$ and $\mathrm{H}_{2} \mathrm{O}$.

Figure $3 \mathrm{c}$ shows Raman spectra of $\mathrm{GO}$ and $\mathrm{rGO}$. Raman spectroscopy was a direct and non-destructive measurement for characterization of disorder structure of graphitic materials. Generally, two characteristic peaks named D $\left(\sim 1355 \mathrm{~cm}^{-1}\right)$ and $G$ $\left(\sim 1580 \mathrm{~cm}^{-1}\right)$ bands were observed in graphite-based materials [32]. The $\mathrm{G}$ band represents the first order scattering of the $\mathrm{E}_{2 \mathrm{~g}}$ photons observed for $\mathrm{sp}^{2}$ carbon domain, while the $\mathrm{D}$ band corresponds to breathing mode or j-point photons of $\mathrm{A}_{1 \mathrm{~g}}$ symmetry associated with disorder band of structural defect, amorphous carbon or edge. The intensity ratio of $D$ band to $G$ band $\left(I_{\mathrm{D}} / I_{\mathrm{G}}\right)$ is usually used as a measure of disorder. For example, the $I_{\mathrm{D}} / I_{\mathrm{G}}$ ratio of $\mathrm{GO}$ and $\mathrm{rGO}$ is 0.83 and 1.33, respectively, as shown in Figure 3c. It is implied that the thermally reduction process converting GO into rGO may increase the intensity of the disordered structure of graphene oxide platelets.

\subsection{Characterization of EET/NEET and their corresponding composites by FTIR spectroscopy}

In this study, FTIR is used to monitor the curing process of EET and NEET. As shown in Figure 4 curve (a), the FTIR spectrum of the EET system before curing was found to exhibit characteristic bands for epoxy ring of DGEBA and primary amine of ACAT (T-404) at the positions of 910 and 3200 $3300 \mathrm{~cm}^{-1}$, respectively. After the programmed heating

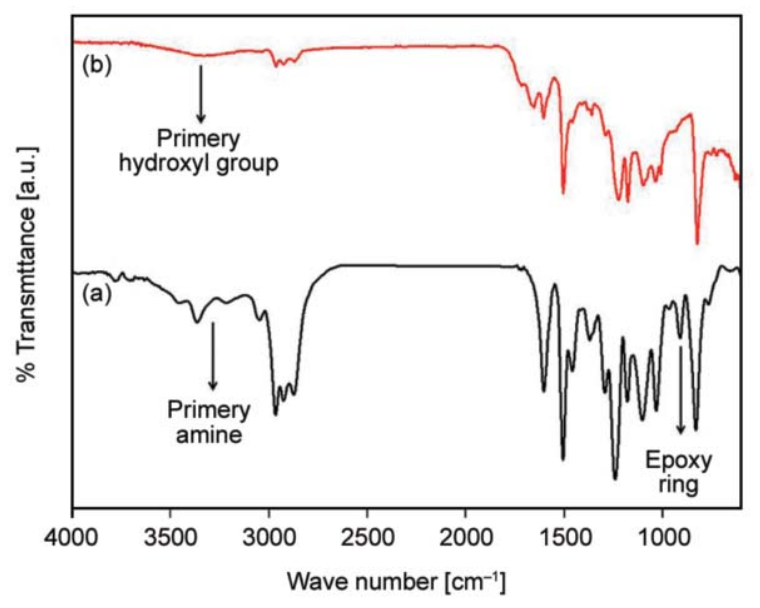

Figure 4. FTIR spectra of the DGEBA cured with ACAT at $120^{\circ} \mathrm{C}$ for (a) 0 and (b) 6 hours (EET system).

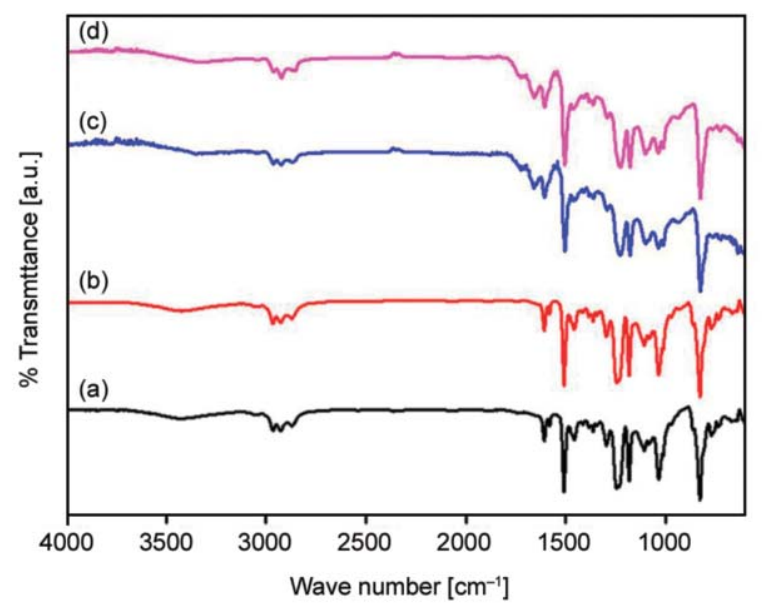

Figure 5. FTIR spectra of (a) rGOEET, (b) GOEET, (c) rGONEET, and (d) GONEET.

treatment at $120^{\circ} \mathrm{C}$ for 6 hours, both characteristic bands of epoxide ring and primary amine disappeared, which indicates a successful thermal epoxy ring-opening polymerization reaction, as shown in Figure 4 curve (b) [36]. FTIR spectrum of NEET system also exhibit the same phenomena.

The EET composites containing $1 \mathrm{wt} \%$ of dispersed rGO and GO platelets are shown in Figure 5 curve (a) and (b), denoted as rGOEET and GOEET. The FTIR spectroscopy of NEET composites containing $1 \mathrm{wt} \%$ of dispersed $\mathrm{rGO}$ and GO platelets are shown in Figure 5 curve (c) and (d), denoted as rGONEET and GONEET. All FTIR spectra exhibit a disappearance of characteristic bands of epoxy ring of DGEBA and primary amine of ACAT/T-403. It indicates that all epoxy thermoset composites were all thermal cured completely. As shown on Figure 6, due to the DSC data, it seem that the GO or rGO in EET resin systems didn't affect the curing process. 


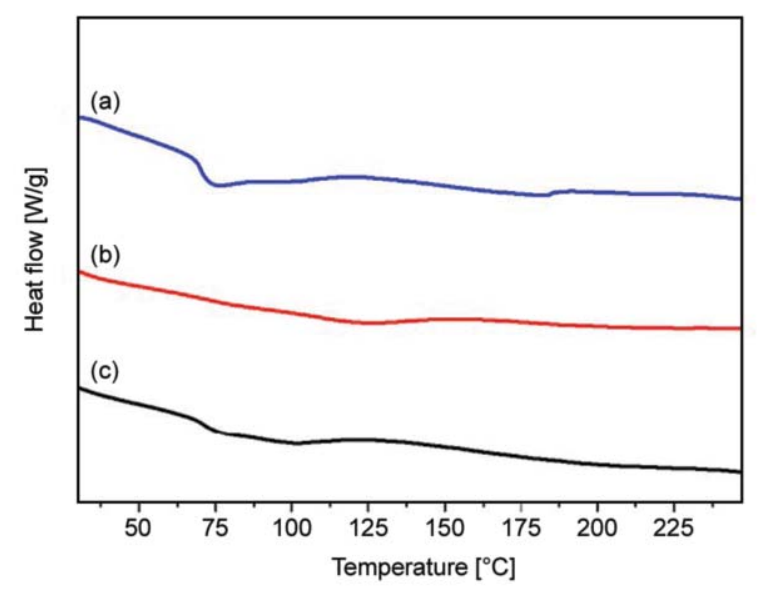

Figure 6. The DSC curve of (a) EET, (b) GOEET, and (c) rGOEET.

\subsection{Morphological studies of EET/NEET composite coatings by TEM}

The morphological studies for dispersion capability of rGO and GO in the EET/NEET composite system was identified using TEM at a magnification of $\times 200000$. The EET composite system, $1 \mathrm{wt} \%$ of dispersed conductive $\mathrm{rGO}$ platelets were found to show a similar dispersion capability to disperse non-conductive GO

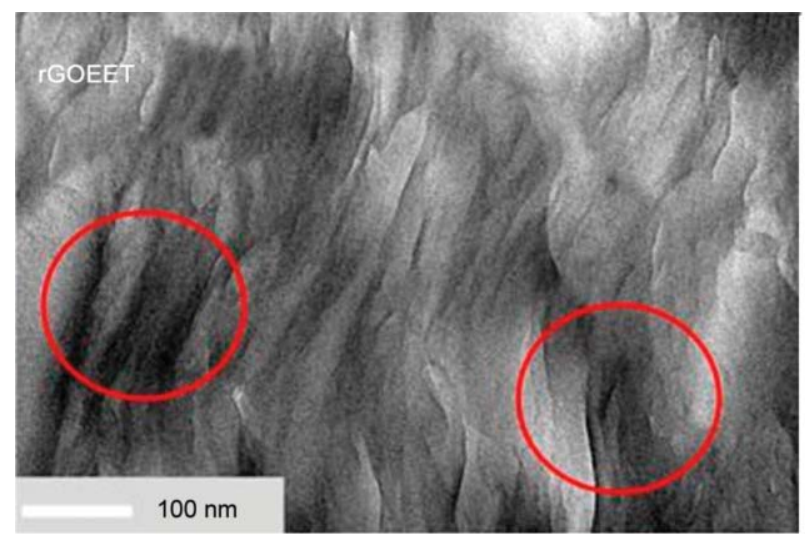

a)

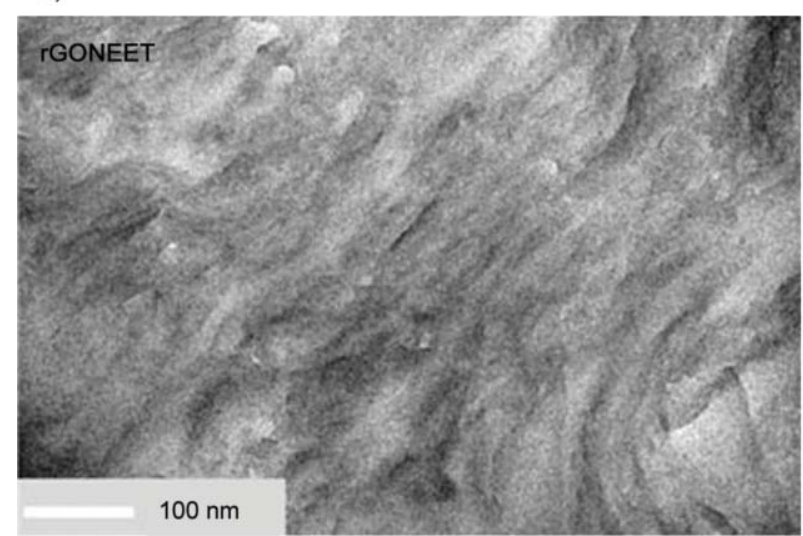

c) platelets, the rGO and GO platelets revealed a heterogeneous distribution (circle places) in the EET composites system, is shown in Figure $7 \mathrm{a}$ and $7 \mathrm{~b}$. On the other hand, the NEET composite system, $1 \mathrm{wt} \%$ of dispersed conductive rGO platelets also exhibit a similar dispersion capability to dispersed nonconductive GO platelets, is shown in Figure $7 \mathrm{c}$ and $7 \mathrm{~d}$. It should be noted that the GO may exhibit a better dispersion capability as compared to rGO in the EET composite system, while in the NEET composite system present similar condition. The dispersion capability of dispersed $\mathrm{rGO}$ and GO platelets in the EET and NEET composites were further identified using oxygen gas permeability analysis (GPA) of asprepared membranes.

\subsection{Oxygen gas permeability of EET/NEET and their corresponding composite membranes measured by GPA}

The Oxygen gas barrier property of EET/NEET and their corresponding composite membranes with $\sim 80 \mu \mathrm{m}$ in thickness were investigated using gas permeability analyzer (GPA), all data were evaluated at least three times, as show in Figure 8 and Table 1.

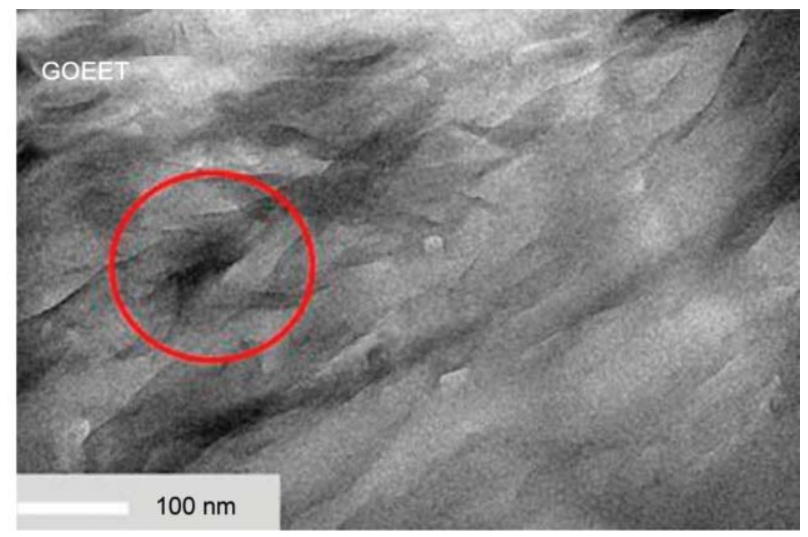

b)

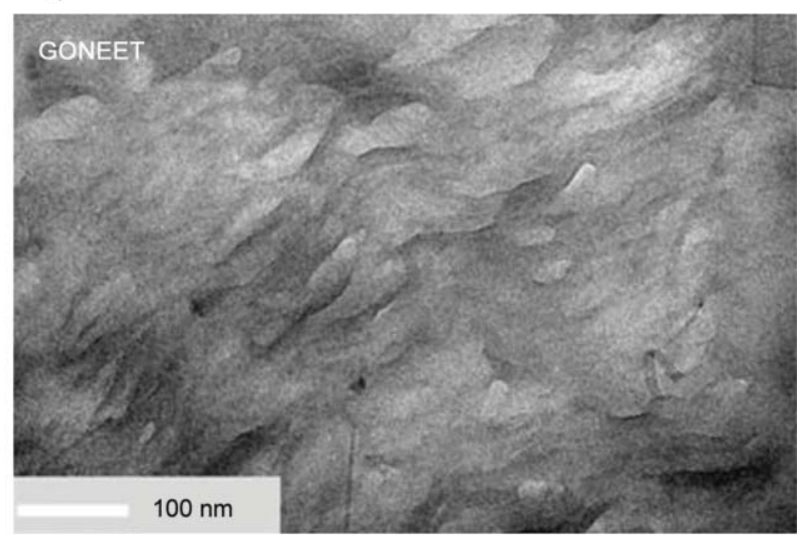

d)

Figure 7. TEM micrographs of (a) rGOEET, (b) GOEET, (c) rGONEET, and (d) GONEET at magnification of $\times 200 \mathrm{k}$. 


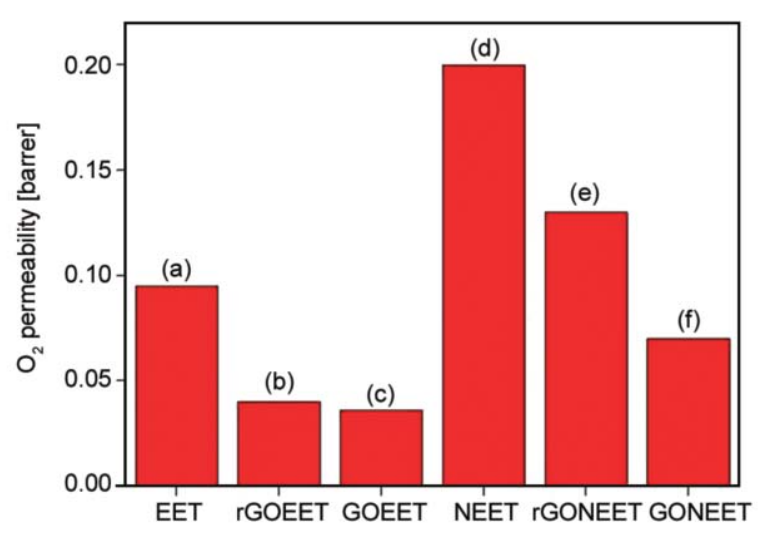

Figure 8. Oxygen permeability of as-prepared epoxy and composite membranes for (a) EET, (b) rGOEET, (c) GOEET, (d) NEET, (e) rGONEET, and (f) GONEET.

Table 1. Electrochemical corrosion and oxygen permeability measurements of EET/NEET and corresponding composite coatings/membranes.

\begin{tabular}{|c|c|c|c|c|}
\hline $\begin{array}{l}\text { Sample } \\
\text { code }\end{array}$ & $\begin{array}{l}E_{\text {corr }} \\
{[\mathrm{mV}]}\end{array}$ & $\begin{array}{c}I_{\text {corr }} \\
{\left[\mu \mathrm{A} / \mathbf{c m}^{2}\right]}\end{array}$ & $\begin{array}{c}\text { Thickness } \\
{[\mu \mathrm{m}]}\end{array}$ & $\begin{array}{c}\mathrm{O}_{2} \text { permeability } \\
\text { [barrer] }\end{array}$ \\
\hline CRS & -1150.6 & 121.20 & - & - \\
\hline NEET & -991.3 & 11.22 & $20 \pm 1$ & $0.202 \pm 0.002$ \\
\hline GONEET & -729.5 & 0.16 & $20 \pm 1$ & $0.070 \pm 0.007$ \\
\hline rGONEET & -841.3 & 3.16 & $20 \pm 1$ & $0.130 \pm 0.001$ \\
\hline EET & -804.2 & 2.01 & $20 \pm 1$ & $0.095 \pm 0.009$ \\
\hline GOEET & -659.0 & 0.12 & $20 \pm 1$ & $0.036 \pm 0.004$ \\
\hline rGOEET & -521.1 & 0.02 & $20 \pm 1$ & $0.040 \pm 0.004$ \\
\hline
\end{tabular}

Oxygen permeability of EET and NEET membrane were found to be 0.095 and 0.202 barrer, respectively, as shown in Figure 8 column (a) and (d). It indicates that the neat EET membrane exhibited a better oxygen barrier property as compared to NEET membrane. It was observed that in both EET/NEET membrane, the dispersed GO platelets $(0.036 / 0.070$ barrier) shows a better oxygen barrier property as compared to dispersed rGO platelets $(0.040 / 0.130$ barrier). It indicates that the GO displayed a better dispersion capability in both EET and NEET membrane than rGO. The better dispersion capability and oxygen barrier property of dispersed GO platelets existed in EET/NEET membrane compared to rGO leads to the formation of GO-based composite as potential candidate for anticorrosion coating, which will be discussed in the following section.

\subsection{Redox property of EET/NEET and their corresponding composite coatings measured by electrochemical $\mathrm{CV}$ studies}

In this study, ITO electrode spinned-coated with EET, NEET and their corresponding composites containing

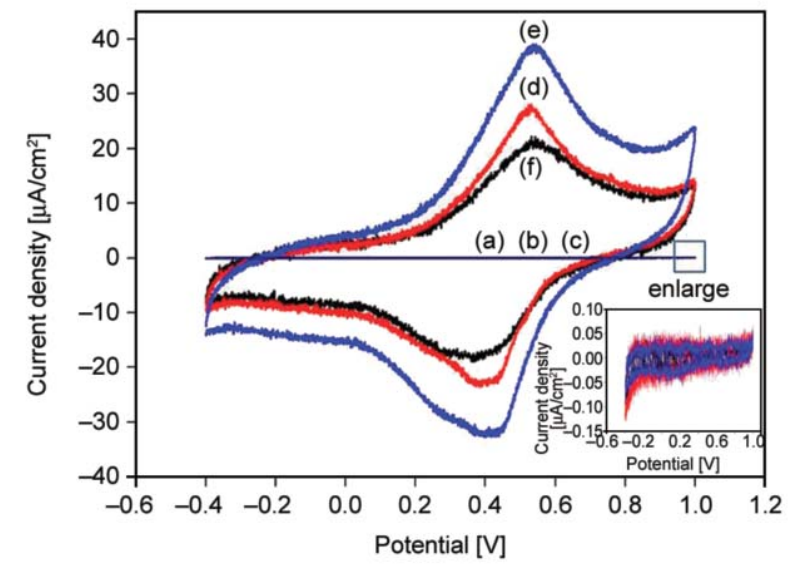

Figure 9. Electrochemical cyclic voltammetric studies of electroactivity for (a) NEET, (b) rGONEET, (c) GONEET, (d) EET, (e) rGOEET, and (f) GOEET as measured in $1.0 \mathrm{~N}$ of $\mathrm{H}_{2} \mathrm{SO}_{4}$ aqueous solution with can rate of $50 \mathrm{mV} / \mathrm{s}$.

$1 \mathrm{wt} \%$ of GO and rGO were investigated using a series of electrochemical cyclic voltammetry $(\mathrm{CV})$ tests. It should be noted that the NEET and their corresponding composites didn't show any redox peak, as shown in Figure 9 curves (a), (b), and (c). However, in the EET coating system, the CV curve of the ITO electrode coated with EET and its corresponding composites shows one single oxidation peak, which was similar to many longer oligomers that undergo a two-electron-transfer process [37]. For example, EET coating was found to reveal the oxidation current $\left(I_{\mathrm{ox}}\right)$ of $26 \mu \mathrm{A} / \mathrm{cm}^{2}$ and the reduction current ( $\left.I_{\mathrm{red}}\right)$ of $22 \mu \mathrm{A} / \mathrm{cm} 2$, respectively, as shown in Figure 9 curve (d). After incorporation of $1 \mathrm{wt} \%$ of dispersed non-conductive GO platelets, the Iox and Ired of GOEET was found to decreases $\left(I_{\mathrm{ox}}=20 \mu \mathrm{A} / \mathrm{cm}^{2}\right.$, $I_{\text {red }}=17 \mu \mathrm{A} / \mathrm{cm}^{2}$ ), as shown in Figure 9 curve (f), indicating that the appearance of non-conductive GO platelets lowers the redox capability of EET coating. However, incorporation of $1 \mathrm{wt} \%$ of dispersed conductive rGO platelets was found to promote the redox ability of the EET $\left(I_{\mathrm{ox}}=40 \mu \mathrm{A} / \mathrm{cm}^{2}, I_{\text {red }}=\right.$ $30 \mu \mathrm{A} / \mathrm{cm}^{2}$ ), as shown in Figure 9 curve (e). It implies that the conductive rGO platelets can functioned as electron transfer bridge between electroactive segments of the EET polymer chains to promote the redox behavior of EET coating. In summary, for the NEET system, there is no any redox behavior of NEET and in its corresponding composite coatings. In the EET system, conductive rGO platelets was found to promote the redox behavor of EET and, non-conductive GO platelets was found to depress the redox behavior of EET. 


\subsection{Potentiodynamic measurements of EET and NEET and their corresponding composite coatings investigated by electrochemical corrosion measurements}

In this study, the corrosion protection of the CRS electrode coated with as-prepared materials were investigated using a series of standard electrochemical potentiodynamic measurements in saline solution. Figure 10 showed Tafel plots for curve (a) the bare CRS electrode and CRS electrode coated with curve (b) NEET, curve (c) GONEET, curve (d) rGONEET, curve (e) EET, curve (f) GOEET, and curve (g) rGOEET. All corresponding data of Tafel plot were summarized in Table 1.

The Tafel plots of the CRS electrode coated with all samples exhibiting corrosion potential $\left(E_{\text {corr }}\right)$ is more positive than bare CRS electrode. On the other hand, corrosion current $\left(I_{\text {corr }}\right)$ of CRS electrode coated with all coating samples were found to be lower than bare CRS electrode. EET coating system was found to reveal a better corrosion protection as compared to EET coating system based on the results of $E_{\text {corr }}$ and $I_{\text {corr. }}$ For example, $E_{\text {corr }}(-804.2 \mathrm{mV})$ and $I_{\text {corr }}$ $\left(2.01 \mu \mathrm{A} / \mathrm{cm}^{2}\right)$ of the EET coating was found to be more positive and smaller as compared to EET $\left(-991.3 \mathrm{mV}, 11.22 \mu \mathrm{A} / \mathrm{cm}^{2}\right)$. The possible mechanism for the better corrosion protection of the EET coating as compared to NEET coating may be due to the electro-catalytic (i.e., redox) behavior of ACAT present in the EET coating, inducing the formation of passive metal oxide layers on the surface of CRS electrode, which protects underlying metallic

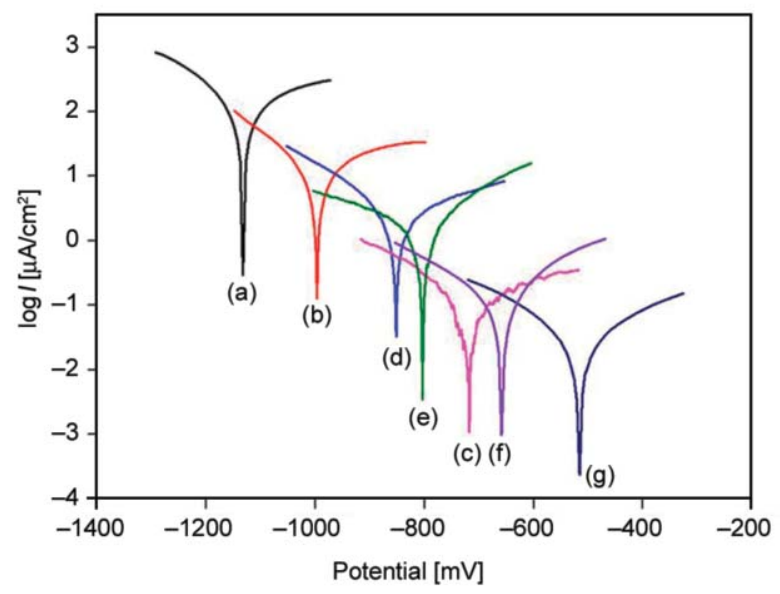

Figure 10. Tafel plots for (a) bare CRS electrode, CRS coated with (b) NEET, (c) GONEET, (d) rGONEET, (e) EET, (f) GOEET, and (g) rGOEET as measured in $3.5 \mathrm{wt} \%$ of $\mathrm{NaCl}$ aqueous solution at room temperature. substrates. After the incorporation of dispersed rGO and GO platelets into the EET and NEET coating, the corrosion protection performance of EET/NEET composite coating was also investigated. It should be noted that in the EET coating system, incorporating $1 \mathrm{wt} \%$ of dispersed $\mathrm{rGO}$ platelets was found to reveal a better corrosion protection than incorporating $1 \mathrm{wt} \%$ of dispersed GO platelets based on the results of the Tafel plots. For example, $E_{\text {corr }}$ $(-521.1 \mathrm{mV})$ and $I_{\text {corr }}\left(0.02 \mu \mathrm{A} / \mathrm{cm}^{2}\right)$ of the rGOEET coating was found to be more positive and smaller as compared to GOEET ( $\left.-659.0 \mathrm{mV}, 0.12 \mu \mathrm{A} / \mathrm{cm}^{2}\right)$. However, in NEET coating system, incorporating $1 \mathrm{wt} \%$ of dispersed GO platelets was found to exhibit a better corrosion protection compared to incorporating $1 \mathrm{wt} \%$ of dispersing rGO platelets. For example, $E_{\text {corr }}(-729.5 \mathrm{mV})$ and $I_{\text {corr }}\left(0.16 \mu \mathrm{A} / \mathrm{cm}^{2}\right)$ of GOEET coating was found to be more positive and smaller as compared to rGOEET $(-841.3 \mathrm{mV}$, $\left.3.16 \mu \mathrm{A} / \mathrm{cm}^{2}\right)$.

The possible mechanism for the corrosion protection of EET composite coatings and NEET composite coatings can be explained as follows: For EET composite coating system, the better corrosion protection of rGOEET coating compared to GOEET coating may be attributed to comparison of synergistic effect of oxygen gas barrier and electro-catalytic property of EET simultaneously through incorporation of $1 \mathrm{wt} \%$ of dispersed rGO and GO platelets into the EET. However, incorporating $1 \mathrm{wt} \%$ of dispersed rGO vs. $1 \mathrm{wt} \%$ of dispersed GO platelets into the EET coating was found to exhibit an oxygen barrier of $0.040 \mathrm{vs} .0 .036$ barrer and the redox property of $I_{\mathrm{ox}}=40 v s . I_{\mathrm{ox}}=20 \mu \mathrm{A} / \mathrm{cm}^{2}$. It shows clearly that in EET composite system, redox behavior of EET may dominate the corrosion protection performance of coatings relative to the oxygen barrier property of coatings.

However, for NEET composite coating system, there is no need to consider the electro-catalytic property of composite coatings. The better corrosion protection of GONEET coating compared to rGONEET coating was related to the better dispersion capability of $1 \mathrm{wt} \%$ of dispersed GO platelets in NEET compared to $1 \mathrm{wt} \%$ of dispersed GO platelets, which leads to a better oxygen gas barrier property (0.070 vs. 0.130 barrer), resulting to a better corrosion protection coating. Moreover, enhancement in the corrosion protection of as-prepared coatings on the CRS electrode were further confirmed using electrochemical 
impedance spectroscopy (EIS), as discussed in following section.

\subsection{Electrochemical impedance spectroscopy measurements}

In this study, EIS is used to evaluate the corrosion protection for the bare CRS electrode and CRS electrode coated with EET/NEET as well as their corresponding composites. Figure 11 shows the Nyquist plots for curve (a) bare CRS electrode and CRS coated with curve (b) NEET, curve (c) GONEET, curve (d) rGONEET, curve (e) EET, curve (f) GONEET, and curve (g) rGOEET. All samples were immersed in $3.5 \mathrm{wt} \%$ of $\mathrm{NaCl}$ aqueous electrolyte for 40 mins before the EIS measurements. The charge transfer resistance of all samples, were determined through the subtraction of the intersection from highfrequency to low-frequency end of the semi-circle arc with real axis, were $0.35,4.04,284.5,84.4,203.9$, 415.4 and $786.7 \mathrm{k} \Omega \cdot \mathrm{cm}^{2}$, respectively. Furthermore, Bode plots (impedance $v s$. frequency) of all samples were shown in Figure 12. $Z_{\text {real }}$ is denoted as the measurement of corrosion resistance. Bode magnitude plots for curve (a) bare CRS electrode and CRS coated with curve (b) NEET, curve (c) GONEET, cueve (d) rGONEETcurve (e) EET, curve (f) GOEET, and cueve (g) rGOEET exhibited the following $Z_{\text {real }}$ values of $2.34,3.63,5.29,4.56,4.86,5.46$ and $5.61 \mathrm{k} \Omega \cdot \mathrm{cm}^{2}$, respectively, at low frequency end. The conclusions obtained from EIS in terms of corrosion protection of CRS electrode coated with EET/NEET composite coating system was consistent with previous studies of Tafel plots.

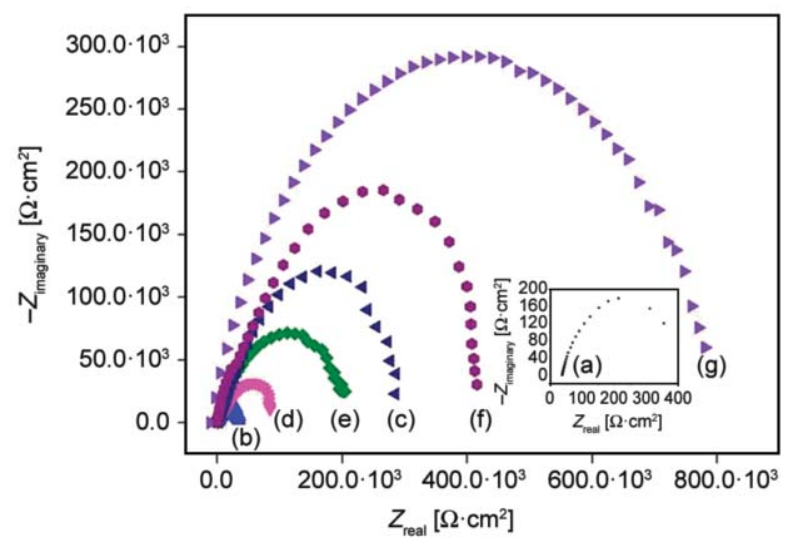

Figure 11. Nyquist plots for (a) bare CRS electrode, CRS coated with (b) NEET, (c) GONEET, (d) rGONEET, (e) EET, (f) GOEET, and (g) rGOEET as measured in $3.5 \mathrm{wt} \%$ of $\mathrm{NaCl}$ aqueous solution at room temperature.

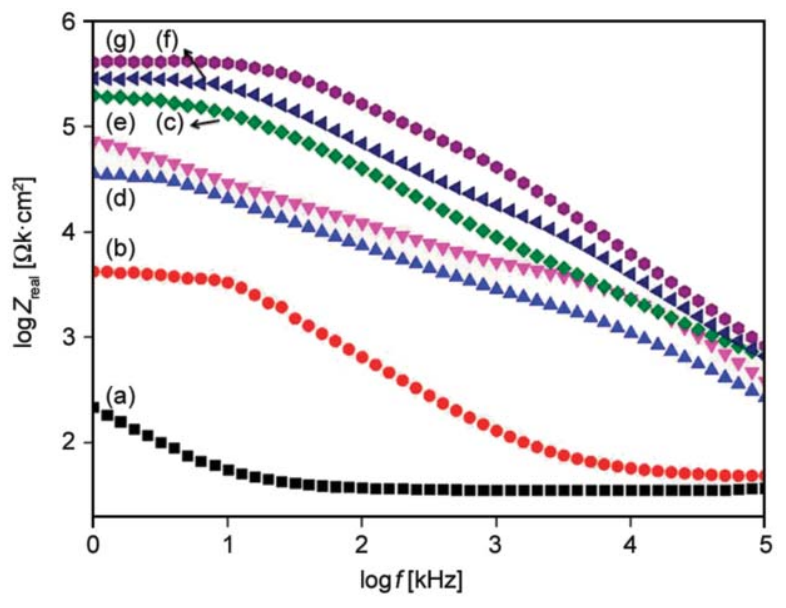

Figure 12. Bode plots for (a) bare CRS electrode, CRS coated with (b) NEET, (c) GONEET, (d) rGONEET, (e) EET, (f) GOEET, and (g) rGOEET as measured in $3.5 \mathrm{wt} \%$ of $\mathrm{NaCl}$ aqueous solution at room temperature.

\subsection{Densely passive metal oxide layer induced by EET and their corresponding composites as confirmed by Raman and ESCA spectroscopy}

Electroactive polymers with reversibly redox characteristic may lead to the formation of passive metal oxide layer to protect the underlying metallic substrates. The surface of outer metal oxide layers induced by electroactive polymers is $\mathrm{Fe}_{2} \mathrm{O}_{3}$ had been identified using Raman spectra [38-40]. In this study, the Raman spectrum of the CRS surface, after detaching the NEET coating, the peak for the passive metal oxide layer was not observed. For the Raman spectrum of CRS surface, after detaching EET coating, it can be observed that the characteristic peaks of $\mathrm{Fe}_{2} \mathrm{O}_{3}$ appeared at the positions of $\sim 219,290$ and $407 \mathrm{~cm}^{-1}$ (i.e., haematite), as shown in Figure 13a. The characteristic peaks of $\mathrm{Fe}_{2} \mathrm{O}_{3}$ formed on the surface of CRS electrode was found to be strengthened and weakened after detaching the rGOEET and GOEET coatings, respectively.

On the other hand, chemical nature of passivation oxide layers induced by the rGOEET coating was further identified using ESCA. It should be noted that the surface of CRS electrode coated with all electroactive coatings exhibited metal oxide layer of $\mathrm{Fe}_{2} \mathrm{O}_{3}$. For example, binding energy $v s$. intensity of iron oxide layers of CRS electrode coated with rGOEET coating was investigated using ESCA, as shown in Figure 13b [41]. These features obtained from ESCA indicates that the formation of densely passive oxide layer was mainly $\mathrm{Fe}_{2} \mathrm{O}_{3}$ [42]. 

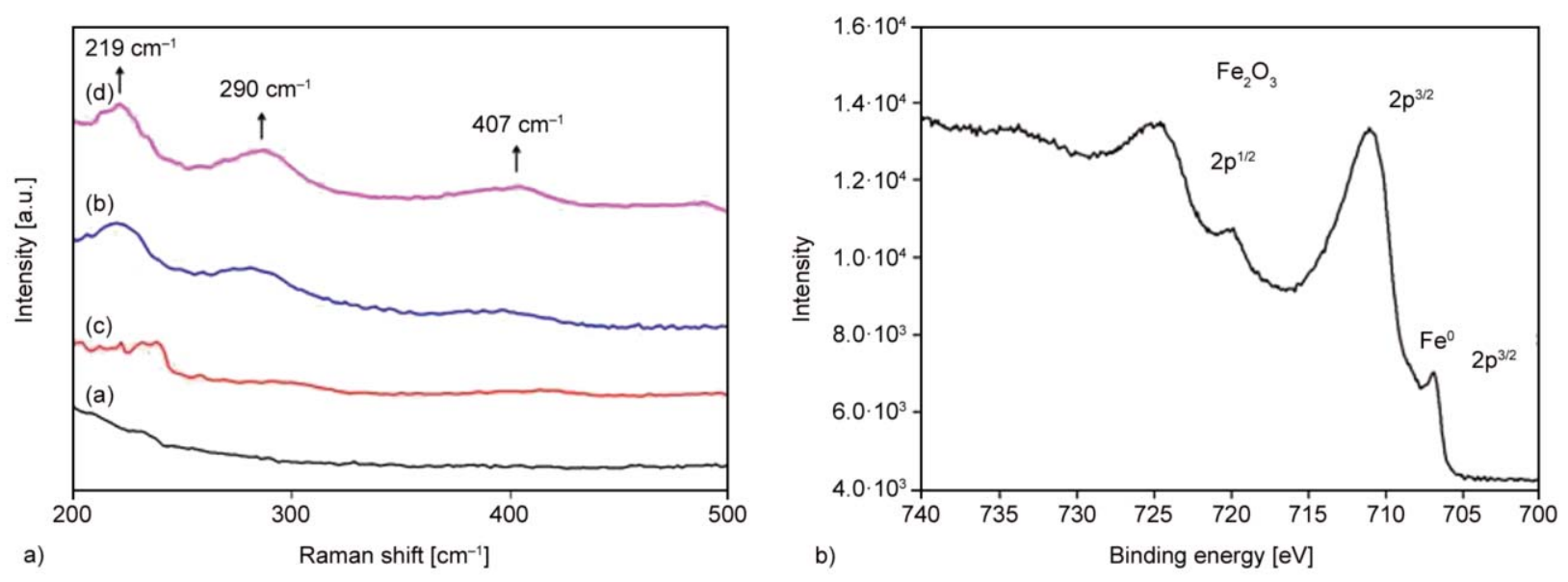

Figure 13. a) Raman spectra for the surface of CRS electrode after detaching the coating of NEET, EET, GOEET, and rGONEET (meaning of curves (a), (b), (c), (d)). b) ESCA Fe 2p core level spectrum for the surface of CRS electrode after detaching the rGOEET coating.

\section{Conclusions}

In this study, we present the first comparative anticorrosion studies for the EET/NEET composites containing conductive rGO and non-conductive GO platelets. GO is synthesized by the typical modified Hummers' method, and then thermally reduced process of $\mathrm{GO}$ was performed to generate conductive rGO. The as-prepared non-conductive GO and conductive rGO was characterized. On the other hand, ACAT was synthesized through oxidative coupling reaction and then further reacted with DGEBA in the DMAc solution with the presence of $1 \mathrm{wt} \%$ of dispersed rGO and GO platelets, and then annealed to produce EET/NEET composites. The as-prepared EET/NEET composites were characterized using FTIR spectroscopy. The dispersion capability of rGO and GO in both EET and NEET composites were further investigated using TEM. Oxygen barrier property of EET and NEET composite membranes were determined using gas permeability analyzer (GPA). The incorporation of $1 \mathrm{wt} \%$ of dispersed GO platelets shows a better oxygen barrier property for both EET and NEET compared to rGO platelets. However, the CV test shows that by incorporating $1 \mathrm{wt} \%$ of dispersed rGO platelets improved the electro-catalytic property of the EET coating while, in the NEET coating system, the redox behavior was not observed. The formation of densely passive metal oxide layer on the CRS electrode was identified through Raman and ESCA spectroscopy.

The comparative anticorrosion studies of CRS electrode coated with EET/NEET composites containing dispersed $1 \mathrm{wt} \%$ of conductive $\mathrm{rGO}$ and non-conductive GO platelets shows that, in EET coating system, incorporating $1 \mathrm{wt} \%$ of dispersed rGO platelets exhibits a better corrosion protection than GO platelets. In addition, the synergistic effect of promoting oxygen barrier property and electro-catalytic property of EET results to a better corrosion protection performance of rGOEET compared to GO platelets. Howev$\mathrm{er}$, in NEET coating system, GONEET have a better corrosion protection due to the better dispersion capability of $1 \mathrm{wt}-\%$ of dispersed GO platelets in the NEET, which leads to a better oxygen barrier property, as confirmed using GPA. Therefore, rGONEET coating was found to exhibit a better corrosion protection compared to GONEET.

\section{Acknowledgements}

The authors acknowledge financial support from the Ministry of Science and Technology, Taiwan, R.O.C. (NSC 102-2632M-033-001-MY3) and (MOST 107-2113-M-033-007); the Department of Chemistry at CYCU; and the Center for Nanotechnology and Center for Biomedical Technology at CYCU.

\section{References}

[1] Vimalanandan A., Lv L-P., Tran T. H., Landfester K., Crespy D., Rohwerder M.: Redox-responsive self-healing for corrosion protection. Advanced Materials, 25, 6980-6984 (2013).

https://doi.org/10.1002/adma.201302989

[2] Andreeva D. V., Fix D., Möhwald H., Shchukin D. G.: Self-healing anticorrosion coatings based on $\mathrm{pH}$-sensitive polyelectrolyte/inhibitor sandwichlike nanostructures. Advanced Materials, 20, 2789-2794 (2008). https://doi.org/10.1002/adma.200800705 
[3] Zhang B., Hu X., Zhu Q., Wang X., Zhao X., Sun C., Li Y., Hou B.: Controllable Dianthus caryophyllus-like superhydrophilic/superhydrophobic hierarchical structure based on self-congregated nanowires for corrosion inhibition and biofouling mitigation. Chemical Engineering Journal, 312, 317-327 (2017).

https://doi.org/10.1016/j.cej.2016.11.147

[4] Vengatesh P., Kulandainathan M. A.: Hierarchically ordered self-lubricating superhydrophobic anodized aluminum surfaces with enhanced corrosion resistance. ACS Applied Materials and Interfaces, 7, 1516-1526 (2015).

https://doi.org/10.1021/am506568v

[5] Zhang E., Cheng Z., Lv T., Qian Y., Liu Y.: Anti-corrosive hierarchical structured copper mesh film with superhydrophilicity and underwater low adhesive superoleophobicity for highly efficient oil-water separation. Journal of Materials Chemistry A, 3, 13411-13417 (2015).

https://doi.org/10.1039/C5TA02053K

[6] Santos J. R., Mattoso L. H. C., Motheo A. J.: Investigation of corrosion protection of steel by polyaniline films. Electrochimica Acta, 43, 309-313 (1998). https://doi.org/10.1016/S0013-4686(97)00052-2

[7] Kalendová A., Sapurina I., Stejskal J., Veselý D.: Anticorrosion properties of polyaniline-coated pigments in organic coatings. Corrosion Science, 12, 3549-3560 (2008).

https://doi.org/10.1016/j.corsci.2008.08.044

[8] Sathiyanarayanan S., Muthukrishnan S., Venkatachari G., Trivedi D. C.: Corrosion protection of steel by polyaniline (PANI) pigmented paint coating. Progress in Organic Coatings, 53, 297-301 (2005).

https://doi.org/10.1016/j.porgcoat.2005.03.007

[9] Yu Y-H., Lai C-Y., Chen C-L., Yeh J-M.: Durable electrochromic coatings prepared from electronically conductive poly(3HT-co-3TPP)-silica hybrid materials. Journal of Electronic Materials, 35, 1571-1580 (2006). https://doi.org/10.1007/s11664-006-0151-8

[10] de Leon A. C. C., Pernites R. B., Advincula R. C.: Superhydrophobic colloidally textured polythiophene film as superior anticorrosion coating. ACS Applied Materials and Interfaces, 4, 3169-3176 (2012).

https://doi.org/10.1021/am300513e

[11] Dai Y., Zhu F., Zhang H., Ma H., Wang W., Lei J.: Electrosynthesis and characterization of polythiophene and corrosion protection for stainless steel. International Journal of Electrochemical Science, 11, 4084-4091 (2016). https://doi.org/10.20964/110376

[12] Nguyen T. L. N., Garcia B., Deslouis C., Xuan Q. L.: Corrosion protection and conducting polymers: Polypyrrole films on iron. Electrochimica Acta, 46, 42594572 (2001).

https://doi.org/10.1016/S0013-4686(01)00699-5

[13] Herrasti P., Ocón P.: Polypyrrole layers for steel protection. Applied Surface Science, 172, 276-284 (2001). https://doi.org/10.1016/S0169-4332(00)00866-7
[14] Wessling B.: Passivation of metals by coating with polyaniline: Corrosion potential shift and morphological changes. Advanced Materials, 6, 226-228 (1994). https://doi.org/10.1002/adma.19940060309

[15] Huang K-Y., Jhuo Y-S., Wu P-S., Lin C-H., Yu Y-H., Yeh J-M.: Electrochemical studies for the electroactivity of amine-capped aniline trimer on the anticorrosion effect of as-prepared polyimide coatings. European Polymer Journal, 45, 485-493 (2009).

https://doi.org/10.1016/j.eurpolymj.2008.10.033

[16] Huang T-C., Yeh T-C., Huang H-Y., Ji W-F., Lin T. C., Chen C-A., Yang T-I., Yeh J. M.: Electrochemical investigations of the anticorrosive and electrochromic properties of electroactive polyamide. Electrochimica Acta, 63, 185-191 (2012).

https://doi.org/10.1016/j.electacta.2011.12.087

[17] Peng C-W., Hsu C-H., Lin K-H., Li P-L., Hsieh M-F., Wei Y., Yeh J-M., Yu Y-H.: Electrochemical corrosion protection studies of aniline-capped aniline trimerbased electroactive polyurethane coatings. Electrochimica Acta, 58, 614-620 (2011).

https://doi.org/10.1016/j.electacta.2011.10.002

[18] Huang K-Y., Shiu C-L., Wu P-S., Wei Y., Yeh J-M., Li W-T.: Effect of amino-capped aniline trimer on corrosion protection and physical properties for electroactive epoxy thermosets. Electrochimica Acta, 54, 5400-5407 (2009).

https://doi.org/10.1016/j.electacta.2009.04.030

[19] Huang K-Y., Weng C-J., Lin S-Y., Yu Y-H., Yeh J-M.: Preparation and anticorrosive properties of hybrid coatings based on epoxy-silica hybrid materials. Journal of Applied Polymer Science, 112, 1933-1942 (2009). https://doi.org/10.1002/app.29302

[20] Weng C-J., Huang J-Y., Huang K-Y., Jhuo Y-S., Tsai M-H., Yeh J-M.: Advanced anticorrosive coatings prepared from electroactive polyimide- $\mathrm{TiO}_{2}$ hybrid nanocomposite materials. Electrochimica Acta, 55, 843084388 (2010). https://doi.org/10.1016/j.electacta.2010.07.063

[21] Yeh J-M., Liou S-J., Lai C-Y., Wu P-C.: Enhancement of corrosion protection effect in polyaniline via the formation of polyaniline-clay nanocomposite materials. Chemistry of Materials, 13, 1131-1136 (2001). https://doi.org/10.1021/cm000938r

[22] Yeh J-M., Liou S-J., Lin C-Y., Cheng C-Y., Chang Y-W., Lee K-R.: Anticorrosively enhanced PMMA-clay nanocomposite materials with quaternary alkylphosphonium salt as an intercalating agent. Chemistry of Materials, 14, 154-161 (2002). https://doi.org/10.1021/cm010337f

[23] Yano K., Usuki A., Okada A.: Synthesis and properties of polyimide-clay hybrid films. Journal of Polymer Science Part A: Polymer Chemistry, 35, 2289-2294 (1997). https://doi.org/10.1002/(SICI)10990518(199708)35:11<2289::AID-POLA20>3.0.CO;2-9 
[24] Lee C., Wei X., Kysar J. W., Hone J.: Measurement of the elastic properties and intrinsic strength of monolayer graphene. Science, 321, 385-388 (2008).

https://doi.org/10.1126/science.1157996

[25] Balandin A. A., Ghosh S., Bao W., Calizo I., Teweldebrhan D., Miao F.: Superior thermal conductivity of single-layer graphene. Nano Letters, 8, 902-907 (2008). https://doi.org/10.1021/n10731872

[26] Orlita M., Faugeras C., Plochoka P., Neugebauer P., Martinez G., Maude D. K., Barra A-L., Sprinkle M., Berger C., de Heer W. A., Potemski M.: Approaching the dirac point in high-mobility multilayer epitaxial graphene. Physical Review Letters, 101, 267601/1267601/4 (2008).

https://doi.org/10.1103/PhysRevLett.101.267601

[27] Compton O. C., Kim S., Pierre C., Torkelson J. M., Nguyen S. T.: Crumpled graphene nanosheets as highly effective barrier property enhancers. Advanced Materials, 22, 4759-4763 (2010). https://doi.org/10.1002/adma.201000960

[28] Chang C-H., Huang T-C., Peng C-W., Yeh J. M., Lu HI., Hung W-I., Weng C-J., Yang T-I., Yeh J-M.: Novel anticorrosion coatings prepared from polyaniline/ graphene composites. Carbon, 50, 5044-5051 (2012). https://doi.org/10.1016/j.carbon.2012.06.043

[29] Yu Y-H., Lin Y-Y., Lin C-H., Chan C-C., Huang Y-C.: High-performance polystyrene/graphene-based nanocomposites with excellent anti-corrosion properties. Polymer Chemistry, 5, 535-550 (2014). https://doi.org/10.1039/C3PY00825H

[30] Hu H., He Y., Long Z. H., Zhan Y. Q.: Synergistic effect of functional carbon nanotubes and graphene oxide on the anti-corrosion performance of epoxy coating. Polymers for Advanced Technologies, 28, 754-762 (2017). https://doi.org/10.1002/pat.3977

[31] Xia W., Xue H. R., Wang J. W., Wang T., Song L., Guo H., Fan X. L., Gong H., He J. P.: Functionalized graphene serving as free radical scavenger and corrosion protection in gamma-irradiated epoxy composites. Carbon, 101, 315-323 (2016). https://doi.org/10.1016/j.carbon.2016.02.004

[32] Kuo S-L., Liu W-R., Kuo C-P., Wu N-L., Wu H-C.: Lithium storage in reduced graphene oxides. Journal of Power Sources, 244, 552-556 (2013). https://doi.org/10.1016/j.jpowsour.2013.01.186

[33] Chang K-C., Huang K-Y., Hsu C-H., Ji W-F., Lai M-C., Hung W-I., Chuang T-L., Yeh J. M.: Synthesis of ultrahigh-strength electroactive polyimide membranes containing oligoaniline in the main chain by thermal imidization reaction. European Polymer Journal, 56, 26-32 (2014).

https://doi.org/10.1016/j.eurpolymj.2014.03.024
[34] Ji W-F., Chang K-C., Lai M-C., Li C-W., Hsu S-C., Chuang T-L., Yeh J-M., Liu W-R.: Preparation and comparison of the physical properties of PMMA/thermally reduced graphene oxides composites with different carboxylic group content of thermally reduced graphene oxides. Composites Part A: Applied Science and Manufacturing, 65, 108-114 (2014).

https://doi.org/10.1016/j.compositesa.2014.05.017

[35] Chang K-C., Ji W-F., Lai M-C., Hsiao Y-R., Hsu C-H., Chuang T-L., Wei Y., Yeh J-M., Liu W-R.: Synergistic effects of hydrophobicity and gas barrier properties on the anticorrosion property of PMMA nanocomposite coatings embedded with graphene nanosheets. Polymer Chemistry, 5, 1049-1056 (2014). https://doi.org/10.1039/C3PY01178J

[36] Wei Y., Jamasbi H., Li S., Cheng S., Jansen S. A., Sein L. T., Jr., Zhang W., Wang C.: Corrosion protection properties of coatings of the epoxy-cured aniline oligomers based on salt spray and UV-salt fog cyclic tests. ACS Symposium Series, 843, 208-227 (2003). https://doi.org/10.1021/bk-2003-0843.ch014

[37] Weng C-J., Chang C-H., Peng C-W., Chen S-W., Yeh J-M., Hsu C-L., Wei Y.: Advanced anticorrosive coatings prepared from the mimicked Xanthosoma sagittifolium-leaf-like electroactive epoxy with synergistic effects of superhydrophobicity and redox catalytic capability. Chemistry of Materials, 23, 2075-2083 (2011). https://doi.org/10.1021/cm1030377

[38] Tian Z., Yu H., Wang L., Saleem M., Ren F., Ren P., Chen Y., Sun R., Sun Y., Huang L.: Recent progress in the preparation of polyaniline nanostructures and their applications in anticorrosive coatings. RSC Advances, 4, 28195-28208 (2014).

https://doi.org/10.1039/C4RA03146F

[39] Gonçalves G. S., Baldissera A. F., Rodrigues Jr. L. F., Martini E. M. A., Ferreira C. A.: Alkyd coatings containing polyanilines for corrosion protection of mild steel. Synthetic Metals, 161, 33-23 (2011). https://doi.org/10.1016/j.synthmet.2010.11.043

[40] Duret A., Grätzel M.: Visible light-induced water oxidation on mesoscopic $\alpha-\mathrm{Fe}_{2} \mathrm{O}_{3}$ films made by ultrasonic spray pyrolysis. The Journal of Physical Chemistry B, 109, 17184-17191 (2005).

https://doi.org/10.1021/jp044127c

[41] Wessling B.: Scientific and commercial breakthrough for organic metals. Synthetic Metals, 85, 1313-1318 (1997).

https://doi.org/10.1016/S0379-6779(97)80254-8

[42] Grosvenor A. P., Kobe B. A., Biesinger M. C., McIntyre N. S.: Investigation of multiplet splitting of Fe $2 p$ XPS spectra and bonding in iron compounds. Surface and Interface Analysis, 36, 1004-1008 (2004).

https://doi.org/10.1002/sia.1984 